\section{Biotechnology}

\section{France now}

A GROUP of French scientists has set up a commercial organization for the exploitation of genetic manipulation. Known as Transgène, the company has an initial capital of 40 million French francs. Although the capital has been provided by industrial companies, the sponsors of the new venture include the CNRS (Centre National de la Recherche Scientifique), L'Institut National de la Recherche Agronomique, L'Institut National de la Santé et de la Recherche Medicale and the Pasteur Institute.

The new organization will be based at its own laboratories near Strasbourg and its policy will be determined by a scientific committee including Professor Philippe Kourilsky from the Pasteur Institute and Professor Pierre Chambon from the Louis Pasteur University of Strasbourg. It is intended that the scientific committee will include some scientists from outside France. The scientific director of the enterprise has been recruited but not yet named.

It is understood, however, that the director is at present the head of research at a European pharmaceutical company and is not French.

The formation of Transgène has been talked of for several months. The capital for the enterprise has been provided by a consortium of companies organized by the Compagnie Financière de Paris et des Pays Bas (Paribas) and includes the oil company Elf, the French liquid air company Air Liquide and the champagne and brandy firm of Moët-Hennessy. The commercial head of the new enterprise will be the director of research at Parisbas, M. Robert Lattès. It appears that this French initiative has been prompted - some would say provoked - by the publicity given in the past few months to the doings of the Swiss- based company Biogen, but the organizers of Transgène also have in mind the steps taken in the United States during the past few years to put genetic manipulation on a commercial footing. Although nothing is known as yet of the work on which Transgène will be engaged, it is expected that the company will be recruiting a staff of between 50 and 80 people, most of whom will be based at the laboratories in Strasbourg.

Transgène appears to have hit on a novel way of reconciling the conflict of interest between university researchers and commercial interests that inevitably arises in such circumstances. Fifteen per cent of the shares are to be held by the sponsors of the enterprise, including the Pasteur Institute and the CNRS. A further eight per cent of the shares will be the property of a foundation yet to be established whose function will be to support basic research in the general field of molecular biology - a task that will become feasible if and when Transgène makes money.

The Strasbourg laboratory will not be completed for two years. In the meantime Transgène is hoping to make arrangements for research to begin on a contract basis in some other laboratory, possibly at the Louis Pasteur University. The scientific staff will be recruited in time to begin work at the turn of the year but the initial scientific objectives will not be defined until the scientific board is complete around October.

\section{University industry}

\section{Surrey consults}

SHORTAGES of funds are increasingly making British universities search for alternative sources of finance. The University of Surrey has in this way branched out beyond the usual pattern of university work. Last week it formally opened a new institute to tackle industrial health and safety problems.

\title{
Poles protest at academic censors
}

SCIENTIFIC publications should be totally exempt from state censorship, according to a report by the Polish "DiP" group (Doswiadczenie i Przyslosc - Experience and the Future). This unofficial body, which includes leading figures from the academic and literary professions, Party and church, was originally established in November 1978 as a discussion group to consider the economic crises facing Poland. Unable to hold the open discussions they had planned, the members of DiP have relied on questionnaires. The first such survey, "Report on the state of the country and ways of putting it right"', was made in May 1979; the second, "How do we get out of this?" in December 1979 and January 1980 . This second report is now in circulation.
Questionnaires were completed by 141 people. (Some of those approached declined to take part saying that they had no faith in the sense of the exercise.) The sample included 65 scientists, of whom 39 were university lecturers and professors - biologists, physicists, mathematicians and agronomists. The result is a penetrating study of the economic and social problems of the Polish People's Republics.

A necessary condition for any reforms to be successful, it says, is that confidence should be restored in the government. To this end, inter alia, a free flow of information is essential. A proper definition of material liable to censorship (military and industrial secrets) should be laid down, and academic publications exempted from the censors.
Surrey's Institute of Industrial and Environmental Health and Safety has actually been operating for 18 months. So far, it has earned about $£ 700,000$, one-third from grants and donations and the rest from specific contracts. According to its director, Professor James Bridges, the institute is already almost entirely selffinancing and hopes eventually to make a profit which can be ploughed back into the university. The members of the institute's staff are either tenured in an academic department, on short-term research council contracts or have been specifically employed by the institute on annual rolling contracts.

The institute is an amalgamation of several different academic units (the Wolfson Bionalytical Unit, the Materials Handling Research Unit, the Industrial Biomedical Unit and the Toxicology Unit). It also includes two new units, the Isolator (Gnotobiotics) Unit and the Occupational Health and Hygiene Service. The last of these is the most unexpected. It carries out no research as such, but aims to provide local industries too small to employ their own specialists with advice on health and safety problems.

The Occupational Health and Hygiene Service appears to be an effective way of making links with local industry. An investigation of sore throats and bronchitis at one local factory led to the Wolfson Bioanalytical Unit being called in to take air samples. It finally identified the source of irritation as chromium carried from one part of the plant to another when the wind was in a particular direction. The Wolfson Unit also solved a problem in the handling of glass fibre resins in a local factory after a similar introduction.

Most of the institute's work so far has been funded by larger organizations. The Materials Handling Unit, for example, has completed an ergonomic study for the EEC of the body stresses caused when men lift heavy objects, and is now doing a similar study of female workers for the UK Health and Safety Executive.

The Isolator Unit was created to build up on a previous collaboration with Vickers Medical Limited to design and make medical isolators out of flexible film. The unit is now designing film units for isolating experimental animals and protecting workers handling drugs and other potentially dangerous materials. The Toxicology Unit is engaged on fundamental work on biochemical pathways in man and animals, but most of its contract work consists of in vitro testing for mutagenesis and carcinogenesis.

The institute acts more as a research association than a university research department. According to its staff, the prospects for the next year or two are good, with plenty of work on hand. Thereafter, the institute will have to live on its wits, helped by whatever reputation it acquires in the meantime.

Judy Redfearn 